\title{
PESCA ARTESANAL NO LITORAL SUL POTIGUAR: PERFIL SOCIOECONÔMICO, DIFICULDADES E PERSPECTIVAS
}

\author{
ARTISANAL FISHING IN SOUTH \\ COAST, RN, BRAZIL: SOCIOECONOMIC \\ PROFILE, DIFFICULTIES AND \\ PERSPECTIVES
}

Luênia Kaline Tavares da Silva

lueniasemarh@hotmail.com

Gestora Ambiental e Mestra em Desenvolvimento e Meio Ambiente pela Universidade Federal do Rio Grande do Norte (UFRN).

Orcid: https://orcid.org/0000-0001-5633-5879

Francisca de Souza Miller

fransmiller56@yahoo.com.br

Professora do Programa de Pós-Graduação em Antropologia Social da Universidade Federal do Rio Grande do Norte (UFRN).

Orcid: https://orcid.org/0000-0003-1739-5152

\section{RESUMO}

A pesca artesanal representa uma das importantes atividades econômicas do Rio Grande do Norte (RN). O município de Arez, localizado no litoral sul do RN, tem forte tradição pesqueira, tanto na exploração de peixes quanto na coleta de mariscos (moluscos) às margens da Lagoa de Guaraíra. Este estudo teve como objetivo delinear o perfil socioeconômico dos pescadores e marisqueiras que vivem nas comunidades de Patané e Camocim. Para tanto, fez-se uso da pesquisa bibliográfica, observação em campo, aplicação de entrevistas e análise da Estatística Descritiva. Entre os meses de janeiro a julho de 2014, foram aplicadas as entrevistas semiestruturadas com 41 e 23 pessoas de Patané e Camocim, respectivamente; totalizando 64 entrevistados. As perguntas incluíram o nível de escolaridade, idade, tempo de trabalho na pesca, cadastro na Colônia de Pesca, forma de comercialização e rendimento mensal. Os resultados indicaram que os entrevistados têm idade entre 40 e 60 anos, possuem apenas o nível de ensino fundamental incompleto, são casados e têm filhos, sobrevivem com um rendimento mensal menor do que um salário mínimo e não recebem o seguro desemprego. As principais dificuldades relatadas na execução de suas atividades são a Colônia de Pesca não ter sede própria e a falta de uma fábrica de beneficiamento para o peixe/marisco. Diante dessa conjuntura, a atividade pesqueira se desenvolve em meio a entraves técnicos, burocráticos e financeiros em que a necessidade cotidiana de homens e mulheres é o fator determinante na disposição de continuar trabalhando na Lagoa de Guaraíra.

Palavras-chave: Pescadores Artesanais. Aspectos Socioeconômicos. Comunidades Pesqueiras. 


\begin{abstract}
Artisanal fishing is one of the important economic activities of Rio Grande do Norte (RN). The municipality of Arez, located in the southern coast of RN, has a strong fishing tradition, in both exploitation of fish and in the harvesting of shellfish (mollusks) on the shores of Guaraíra Lagoon. This study aimed to describe the socioeconomic profile of fishermen and marisqueiras (mollusk fisherwomen) who live in the communities of Patané and Camocim. For this purpose, it was used bibliographic research, field observation, interviews and descriptive statistics analysis. Between the months of January to July 2014 were applied semi-structured interviews with 41 and 23 people of Patané and Camocim respectively; a total of 64 respondents. The questions included level of education, age, fishery work time, registration in Fishing Colony, form of marketing and monthly income. The results indicated that the interlocutors are aged 40 to 60 years; have only completed elementary school level; are married and have children; survive on less than a minimum wage income and they are not receiving employment insurance. The main difficulties reported in the execution of their activities is that the Fishing Colony does not have its own headquarters, neither does it have an improvement factory for fish/shellfish. Therefore, the fishery develops on technical, bureaucratic and financial obstacles, where daily needs of men and women are the determining factor in willingness to continue working in Guaraíra Lagoon.
\end{abstract}

Keywords: Artisanal Fishers. Socioeconomic Aspects. Fishing Communities.

\title{
INTRODUÇÃO
}

A modalidade da pesca artesanal é responsável por grande parte dos recursos pesqueiros capturados no mundo e emprega aproximadamente 51 milhões de pessoas, proporcionando ocupação à maioria dos pescadores, especialmente àqueles concentrados em países tropicais (FAO, 2012).

No Brasil, a pesca artesanal é uma atividade desenvolvida por toda a extensão litorânea, mas, além dos limites costeiros, a pesca desenvolvida nessa modalidade também ocorre em águas lacustres e fluviais, onde é realizada por meio de botes pequenos e canoas, movidos à vela ou por remos (OLIVEIRA; SILVA, 2012).

Os pescadores artesanais espalhados pelo litoral brasileiro têm seu modo de vida resumido à pesca praticada com autonomia e em pequena escala, cuja produção é em parte consumida pela família e em parte comercializada (DIEGUES, 2004). Para a maior parte desses pescadores, o conhecimento é passado de pai para filho ou pelas pessoas mais velhas e experientes de suas comunidades. Atrelados a esses aspectos, eles bem conhecem o ambiente onde trabalham, quer seja o mar, as marés, os manguezais, os rios ou as lagoas (MPA, 2013).

Em todo o Nordeste do Brasil, a pesca artesanal possui grande representatividade econômica e social para os que vivem da atividade. No Rio Grande do Norte (RN), estado com $410 \mathrm{~km}$ de extensão costeira, que possui 98 comunidades litorâneas distribuídas em 25 municípios, existe 65 mil pessoas empregadas direta ou indiretamente na atividade pesqueira (MPA, 2012; IBAMA, 2010).

A pesca artesanal potiguar se desenvolve com o uso de tecnologias simples, regime de trabalho autônomo, baixos lucros comerciais, dependência de intermediários e propriedade dos instrumentos de pesca (IDEMA, 2004). Além disso, a pesca no RN é a principal fonte de proteínas e renda para aproximadamente 30 mil pescadores, dos quais $30 \%$ são representados pelas mulheres marisqueiras (MPA, 2010). 
Nos últimos anos, foram realizados alguns trabalhos científicos no litoral potiguar sobre a temática da pesca artesanal, destacando-se as pesquisas em Barra de Tabatinga (Nísia Floresta/RN), em relação à organização social dos pescadores (MILLER, 2002); no município de Tibau do Sul, onde foi feita uma análise da influência do Turismo na atividade pesqueira (SILVA, 2011); nas comunidades costeiras de Barra do Cunhaú e Baía Formosa, sobre os processos de fragmentação da pesca artesanal (SILVA, 2012), e nas comunidades de Patané/Camocim (Arez/RN), sobre os aspectos da adaptação dos pescadores e coletoras aos manguezais, realizada entre os anos 2002 e 2003 e publicada por Miller (2012).

As pesquisas supracitadas possuem grande relevância para o entendimento da dinâmica da pesca no litoral sul do RN. No entanto, ainda existem lacunas de informações em relação aos pescadores e marisqueiras, especialmente no que diz respeito à situação socioeconômica e as dificuldades que esses homens e mulheres enfrentam no seu cotidiano. Diante dessas circunstâncias, novos estudos que preconizem traçar um perfil socioeconômico por meio da interlocução discursiva dos próprios pescadores e marisqueiras (interlocutores), serão fundamentais para o esclarecimento dessas lacunas persistentes.

Nessa perspectiva, o presente artigo tem o objetivo de delinear o perfil socioeconômico de pescadores e marisqueiras em duas comunidades localizadas no município de Arez, litoral sul do RN. Foi selecionada a população situada em Patané e Camocim, que possui cerca de 2.000 pessoas dependentes da pesca artesanal e da extração de moluscos para a sua sobrevivência, além de essas atividades gerarem emprego e renda para 350 famílias locais (IDEMA, 2008).

Este artigo configura-se como base de análise em um contexto de mudanças socioambientais nos últimos anos, visto como as duas comunidades pesquisadas realizam a pesca no estuário da Lagoa de Guaraíra que, no ano de 1999, foi decretada como Área de Proteção Ambiental Bonfim-Guaraíra. Entretanto, nos últimos 15 anos, o estuário tem sofrido impactos devido à coexistência de outras atividades econômicas instaladas na região, bem como pela extração predatória dos moluscos. Esses problemas vêm provocando mudanças no ecossistema estuarino, com reflexos e transformações diretas sobre as características socioeconômicas de seus habitantes e na atividade pesqueira.

\section{CARACTERIZAÇÃO DA ÁREA DE ESTUDO}

O município de Arez localiza-se no litoral sul do estado do Rio Grande do Norte. A sede municipal está a $58 \mathrm{~km}$ da cidade de Natal (capital do estado). Limita-se ao norte com os municípios de Nísia Floresta e São José de Mipibu, ao sul com Goianinha e Tibau do Sul, ao leste com Senador Georgino Avelino e Tibau do Sul, e ao oeste com São José de Mipibu e Goianinha (Figura 1).

As comunidades de Patané e Camocim estão inseridas na porção leste do município de Arez (Figura 1). Os principais acessos às duas comunidades são pela Rodovia Federal (BR-101) e pelas Rodovias Estaduais (RN-061 e RN-002). Segundo informações da Prefeitura Municipal (2013), as duas comunidades compreendem aproximadamente 2.000 (dois mil) habitantes, em sua maioria, nativos e - em menor número - nascidos em municípios vizinhos, como Senador Georgino Avelino e Nísia Floresta. 


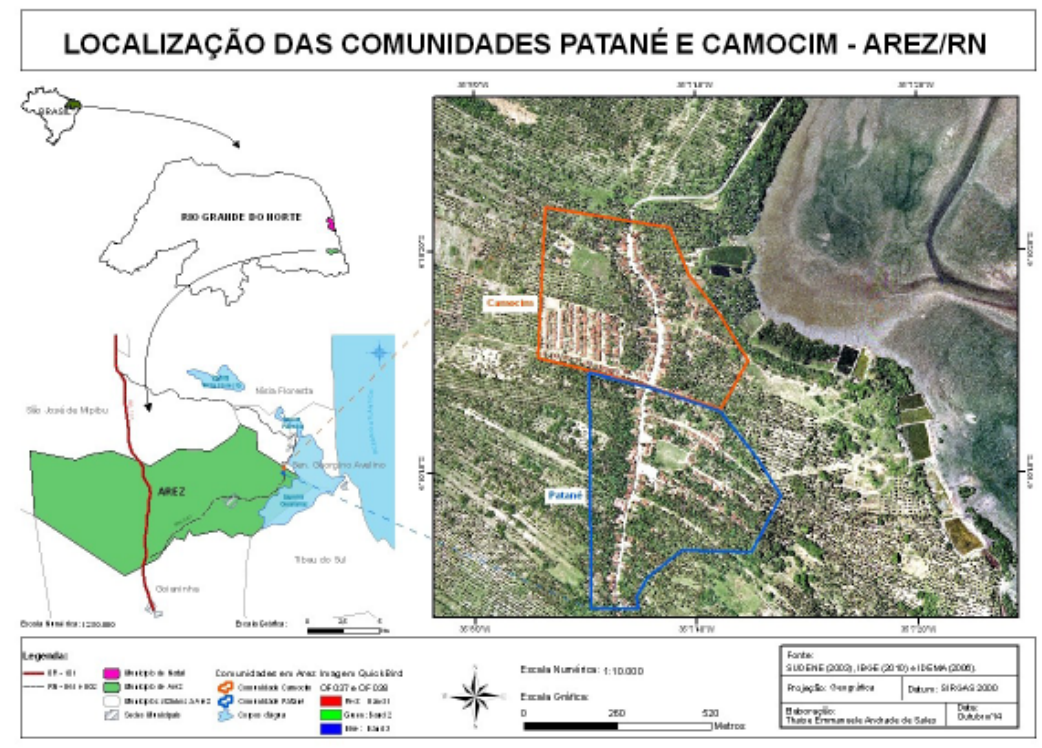

Fonte: Sales, 2014.

De acordo com dados da Prefeitura local, e as narrativas as principais atividades econômicas são a pesca e a extração de moluscos e crustáceos. Na região estuarina, além da pesca tradicional, coexiste a carcinicultura (criação de camarão em viveiros), situada às margens da Lagoa de Guaraíra.

O município de Arez possui as condições hidrológicas e climáticas ideais para o desenvolvimento de atividades nos estuários, possuindo em sua bacia hidrográfica o Complexo Lagunar Bonfim-Guaraíra. Essa Área de Proteção Ambiental (APA Bonfim-Guaraíra), unidade de conservação de uso sustentável representativa dos ecossistemas costeiros e integrantes da Reserva da Biosfera da Mata Atlântica, foi criada pelo Decreto Estadual no 14.369 de 22 de março de 1999, com área de 42.000 hectares, abrangendo os municípios de São José de Mipibu, Nísia Floresta, Senador Georgino Avelino, Goianinha, Arez e Tibau do Sul (IDEMA, 2008).

A região lagunar é considerada rasa, com profundidade variando de 0,5 metro a 2,0 metros, e apesar da forte influência das marés, possui águas tranquilas. Devido a essas características, a pesca artesanal é praticada em embarcações de pequeno porte, exclusivamente por canoas movidas a remo. De acordo com Miller (2012), como as canoas não são motorizadas, o seu raio de ação é limitado e os pescadores das áreas de mangue têm receio de avançar para o mar aberto.

As principais armadilhas utilizadas para capturar as espécies de peixes são a tainheira (rede de emalhar de superfície), a tarrafa e a rede de tresmalho, utilizadas normalmente nas áreas marginais do estuário. Quanto às técnicas para extração dos moluscos e crustáceos, dependem da espécie que se quer capturar, mas geralmente é feita coleta manual ou utilizando objetos cortantes.

As comunidades de pesca geralmente são consideradas de pequena escala devido ao sistema de produção e venda serem direcionadas apenas à sobrevivência. Inserem-se também nessa caracterização os instrumentos de trabalhos adotados e confeccionados pelos participes dessas agremiações sociais estudadas, visto como a construção de canoas e o reparo de redes e tarrafas, 
além da comercialização de armadilhas para pesca, são feitas, sobretudo, pelos pescadores mais antigos.

\section{METODOLOGIA}

Utilizou-se a abordagem qualitativo-quantitativa para a obtenção de dados primários relacionados ao perfil socioeconômico dos interlocutores, pois segundo Flick (2009) e Chizzotti (2010), essas interpelações não são excludentes ou contrárias, mas complementam-se umas às outras no processo de compreensão da realidade.

A abordagem quantitativa proporcionou uma descrição mais percentual das opiniões. Já a qualitativa permitiu uma investigação mais detalhada, coletando principalmente dados observacionais e os discursos nas entrevistas (CRESWELL, 2010).

No intuito de facilitar os contatos com os interlocutores e definir uma amostra proporcional e confiável com a quantidade de pescadores e marisqueiras existentes nas duas comunidades, a pesquisa utilizou o número total de cadastrados ( $\mathrm{n}=200)$ na Colônia de Pesca $(\mathrm{Z}-29)$ para dividir os estratos da amostra concernentes às comunidades de Patané $(n=82)$ e Camocim $(n=46)$.

De acordo com Correa (2003), na amostra estratificada a população pode ser dividida em categorias, que estão representadas na mesma proporção em que existem na realidade. A quantidade de cada unidade amostral foi definida de acordo com o número total de cada estrato das comunidades, e utilizou-se a proporção de $50 \%$. Desse modo, o número de entrevistados das comunidades de Patané $(n=41)$ e Camocim $(n=23)$ representam $50 \%$ da amostra real das duas comunidades, totalizando $(n=64)$ entrevistados.

Por conseguinte, foram aplicadas entrevistas semiestruturadas, compostas por perguntas abertas e fechadas sobre a situação socioeconômica e o cotidiano da pesca local, no período de janeiro a julho de 2014. Ao longo de seis meses, buscou-se coletar informações para traçar o perfil socioeconômico dos entrevistados e discutir sobre as dificuldades e perspectivas dos interlocutores.

Na opinião de Beaud e Weber (2007), as entrevistas são muito utilizadas na pesquisa em campo, principalmente, quando se busca conhecer o ponto de vista dos interlocutores, permitindo-lhes descrever seu cotidiano. Segundo Angrosino (2009) e Matos (2001), as entrevistas semiestruturadas utilizam perguntas relacionadas aos campos de interesse da pesquisa e contribuem na análise dos dados quantitativos e qualitativos.

As perguntas realizadas permitiram identificar a importância econômica e social da pesca para as comunidades, baseadas em dados referentes ao nível de escolaridade, à idade, ao tempo de atuação na pesca, ao modo como praticam a atividade pesqueira (individual, familiar ou em grupo), a participação na Colônia de Pesca, a comercialização e a extração do rendimento mensal.

Após a coleta dos dados em campo, as variáveis socioeconômicas foram organizadas, tabuladas e sistematizadas, por meio da Estatística Descritiva, para a geração de gráficos e tabelas de distribuição de frequência (ANGROSINO, 2009). Paralelamente, as enunciações obtidas nas entrevistas foram analisadas e classificadas nas categorias de dificuldades ou perspectivas apontadas pelos interlocutores. 


\section{RESULTADOS E DISCUSSÕES}

A importância da pesca artesanal para as duas comunidades pesquisadas se reflete no cotidiano dos interlocutores, o qual está intimamente ligado às atividades realizadas na Lagoa de Guaraíra, estuário popularmente chamado de "maré" pelos habitantes locais.

Do total de entrevistados, a maioria foi constituída de homens $76 \%$ em Patané e 70\% em Camocim. A predominância do sexo masculino na atividade pesqueira também foi encontrada nos estudos de Pereira; Filho; Ribeiro; Pinheiro; Nunes \& Costa (2006), Souza; Arfelli \& Graça Lopes (2009) e Alencar e Maia (2011).

As mulheres representaram $24 \%$ da amostra em Patané e 30\% em Camocim. A maior representatividade feminina na comunidade de Camocim se justifica no passado, pois as principais famílias de marisqueiras residiam em sua maioria nessa comunidade, a qual se localiza em terras mais baixas, próximas à maré, o que facilitava o transporte a pé e com a carga dos mariscos sobre a cabeça. As mulheres marisqueiras geralmente são casadas com pescadores e realizam a extração dos moluscos como forma de complementar a renda familiar (MILLER, 2012).

Sobre o estado civil dos interlocutores, predominaram os casados, com $71 \%$ em Patané e $78 \%$ em Camocim. Em outros estudos de Santos; Almeida-Funo; Piga; França; Torres \& Melo (2011); Oliveira (2012) e Freitas; Pamplin; Legat; Fogaça \& Barros (2012) na Região Nordeste do Brasil, também predominam a categoria dos casados entre os pescadores e marisqueiras. Outra minoria dos interlocutores (cerca de 10\%), disse ter união estável, ou seja, não são casados oficialmente, mas dividem a moradia e as contas com outro integrante da família que, geralmente, também é o pai ou a mãe dos seus filhos.

As famílias são, em sua maioria, de tradição pesqueira. Em Patané, 96\%, e Camocim, $83 \%$ dos interlocutores afirmaram ter aprendido a pescar com os pais e avós; é o saber tradicional passado de geração em geração. Segundo Miller (2012) tanto meninos quanto meninas começam a pescar e a coletar mariscos desde muito cedo nas mencionadas comunidades. Devido a esse caráter pesqueiro tradicional nesses espaços coletivos, a pesca foi e ainda é uma atividade essencial para a sobrevivência, como podemos perceber nos discursos a seguir:

"Minha profissão é essa... nasci pescador e vou morrer pescador." (Entrevistado $n^{\circ} 5$ - Pescador há 55 anos)

"Criei-me aqui... e meu sonho é tá na maré pegando liliu"." (Entrevistada $\mathrm{n}^{\circ} 7$ - Marisqueira há 40 anos)

A dependência econômica exclusiva da atividade pesqueira foi declarada por $78 \%$ dos entrevistados de Patané e $74 \%$ dos de Camocim. Os demais interlocutores exercem a pesca como forma de lazer e possuem renda fixa de pensão ou aposentadoria.

A pesca pode ser realizada todo o ano, porém, segundo os pescadores, há períodos de "maré grande" (profunda) em que se torna mais difícil encontrar peixe em grande quantidade no estuário, geralmente entre março e julho.

Para a extração dos moluscos, segundo as marisqueiras, o pior período é quando ocorrem fortes chuvas (enchentes), pois os mariscos são frágeis e não sobrevivem na água doce, mas nos últimos anos a quantidade de lilius aumentou na maré, conforme relata a marisqueira: 
"Vender moluscos aqui é melhor do que vender peixe, porque aumentou os lilius e diminuiu os peixes." (Entrevistada n 1 - Marisqueira há 25 anos)

Em relação à forma como praticam a pesca, $63 \%$ dos entrevistados em Patané e 47\% em Camocim preferem realizar a pesca estuarina individualmente. Esses dados retratam a autonomia do pescador local, pois todos os entrevistados afirmaram possuir canoa e armadilhas próprias, não necessitando mais partilhar o pescado e dividir o lucro da venda com outros pescadores. Segundo relatos, isso foi possível devido ao aumento do uso da tarrafa como principal armadilha, já que esse instrumento facilita o exercício individual da pesca.

Em contrapartida, as marisqueiras trabalham em parceria com outros membros da família, geralmente com as filhas, as irmãs e os esposos. Nas duas comunidades, todas as entrevistadas afirmaram ir acompanhadas para a maré. Esse fato também foi constatado nos estudos de Dias; Rosa \& Damasceno (2007), Oliveira (2012) e Freitas; Pamplin; Legat; Fogaça \& Barros (2012), em que a mariscagem era sempre realizada em parceria com membros da família, geralmente os parentes mais próximos, como o companheiro ou os filhos.

A pesca artesanal é uma atividade que não exige alto nível de escolaridade para aqueles que a exercem, tanto é que mais de $50 \%$ dos interlocutores das comunidades de Patané e Camocim possuem apenas o Ensino Fundamental Incompleto, e o número de analfabetos correspondeu a $47 \%$ do total de entrevistados. Os níveis de escolaridade encontrados não diferem de outras pesquisas realizadas no litoral do RN por Vasconcelos et al. (2003), Dias; Rosa \& Damasceno (2007) e Miller (2012), e em outras regiões do Brasil, por Pereira; Filho; Ribeiro; Pinheiro; Nunes \& Costa (2006), Pereira; Silva \& Costa (2006), Souza; Arfelli \& Graça Lopes (2009), Alencar e Maia (2011), Harayashiki; Furlan \& Vieira (2011) e Lima; Doria \& Freitas (2012).

A pouca escolaridade entre os pescadores e marisqueiras os relaciona ainda mais com a total dependência da atividade pesqueira, já que não possuem qualificação exigida para trabalhar em atividades diferenciadas. Geralmente, como a pesca é uma função passada de pai para filho desde muito cedo e em meio a dificuldades financeiras, isso dificulta conciliar os estudos com o cotidiano pesqueiro, como podemos perceber nos seguintes relatos:

\footnotetext{
"Minha vida desde menino foi só essa de maré... eu tinha até inveja dos meninos que estudavam... chorava e tudo... mas meu pai não queria saber de estudo não...” (entrevistado n 28 - Pescador há 60 anos)
}

\footnotetext{
"Estudei pouco... Fui pra escola, mas naquela época as coisas eram tudo mais difícil... e minha mãe não tinha condições de comprar um caderno... um lápis... não cheguei a terminar a $1^{\mathrm{a}}$ série." (Entrevistada $\mathrm{n}^{\mathrm{o}} 3$ - Marisqueira há 33 anos)
}

As idades dos pescadores e marisqueiras variaram entre 30 e 76 anos. Considerando-se as faixas etárias, verifica-se uma maior participação dos entrevistados de Patané na faixa de 51 a 60 anos (34\%) e em Camocim de 41 a 50 anos $(39 \%)$, conforme demonstrado na Figura 2. Dados semelhantes foram encontrados nos estudos socioeconômicos de Souza; Arfelli \& Graça Lopes (2009), Harayashiki; Furlan \& Vieira (2011), Santos; Almeida-Funo; Piga; França; Torres \& Melo (2011); Freitas; Pamplin; Legat; Fogaça \& Barros (2012) e Lima; Doria \& Freitas (2012). 
Figura 2 - Distribuição segundo a frequência das faixas etárias de pescadores e marisqueiras das comunidades de Patané e Camocim, Arez/RN

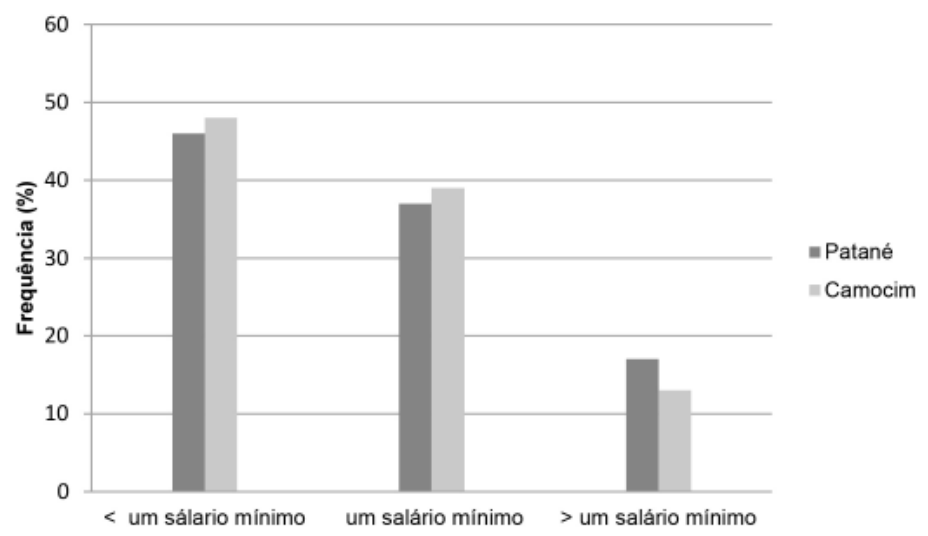

Fonte: Resultados da pesquisa de campo, 2014.

Esses dados revelam que a rotina pesqueira nas duas comunidades é exercida por profissionais mais velhos, pois os pais não estimulam seus filhos a continuarem na pesca devido às dificuldades existentes. Além disso, como alertam Capelesso e Cazella (2011), a atividade pesqueira não apresenta mais uma continuidade familiar, pois os jovens estão perdendo o interesse pela pesca e preferem trabalhar em outras atividades, no intuito de obter uma renda fixa e melhores oportunidades de emprego.

A pesca artesanal é a principal atividade econômica e de subsistência para as comunidades pesquisadas. Devido a esse fator, os interlocutores apresentaram longos anos de dedicação à vida na maré. O tempo de ofício na pesca e mariscagem variou de 12 a 62 anos para os entrevistados de Patané e, entre 15 a 65, para os de Camocim.

Segundo o representante da Colônia de Pesca (Z-29) o longo tempo de dedicação à pesca e à mariscagem se justifica pela falta de alternativas econômicas locais. Com relação às oportunidades de emprego em nível de município, destacam-se: as atividades pesqueiras, os empregos na Prefeitura Municipal, que são na maioria das vezes indicados por relações políticas, e, também na Usina Estivas (produtora e processadora de cana-de-açúcar), mas que em 2007 foi vendida a um importante grupo sucroalcooleiro estrangeiro e por isso, demitiu muitos trabalhadores locais.

A comercialização do pescado nas comunidades é feita diretamente ao consumidor ou aos atravessadores. Em Patané, $73 \%$ dos entrevistados relataram vender o pescado na própria comunidade e os outros $27 \%$ repassam ao atravessador local denominado de "marchante". Na comunidade de Camocim, $68 \%$ vendem diretamente ao consumidor e $32 \%$ repassam ao marchante.

Os mariscos também são vendidos diretamente aos consumidores locais, porém, desde 2012, têm ocorrido mudanças quanto à forma de comercialização dos lilius nas comunidades.

A cadeia de comercialização se tornou mais extensa, devido à participação de atravessadores pernambucanos. Segundo relatos dos interlocutores, depois que os pernambucanos descobriram as comunidades de Patané e Camocim e, consequentemente, a fartura de mão de obra local e de moluscos no estuário da Lagoa de Guaraíra, as formas de extração e venda foram intensificadas, no intuito de atender a demanda externa, como se pode analisar no discurso das irmãs marisqueiras: 
“Às vezes tiro $5 \mathrm{~kg}, 10 \mathrm{~kg}, 20 \mathrm{~kg}$ por dia na maré... o preço de $1 \mathrm{~kg}$ é $\mathrm{R} \$ 5,50$ que o homem paga a gente. É um rapaz de Pernambuco. Eles vêm tanto comprar, quando pegar também. Eles pegam muito, até de 60 kg." (Entrevistada no 34 - Marisqueira há 45 anos)

"O que consigo tirar, depende da maré... quando é maré grande tiramos mais, maré pequena dá menos... eu agora só tiro liliu... a gente tá vendendo $1 \mathrm{~kg}$ a $\mathrm{R} \$ 7,00$ reais na porta. Mas vendemos $1 \mathrm{~kg}$ a $\mathrm{R} \$ 5,00$ reais para esse homem de Recife... ele vem de $08 \mathrm{em} 08$ dias... às vezes ele vem no domingo... espera a gente tirar e vai embora no dia seguinte, para vender lá... como a viagem é longa, ele tem que levar bastante..." (entrevistada $n^{\circ} 3$ - Marisqueira há 33 anos)

Após analisar esses relatos, percebe-se que a extração dos moluscos nas duas comunidades na atualidade, não se caracteriza apenas como uma atividade tradicional como era no passado, visando o alimento para as famílias e a comercialização local, mas sim, como uma atividade comercial, a fim de abastecer um mercado externo às comunidades. Essa transformação da atividade de subsistência em atividade comercial também já havia sido constatada por Woortmann (1992) no litoral norte do RN, quando a coleta do consumo familiar foi substituída para a venda e crescentemente mediada pelo mercado.

Assim, corroborando a opinião de Woortmann (1991) ocorreu a modificação de um tempo de fartura não mediada pelo dinheiro, para a de um tempo de pobreza, onde o dinheiro é o mediador fundamental, o tempo da ambição. Porém, na opinião das marisqueiras, a inserção dos pernambucanos trouxe melhorias, pois eles são considerados compradores fixos dos lilius, já que encomendam uma quantidade definida dos moluscos. Para essas mulheres, a vinda dos pernambucanos para as comunidades é relatada com muita satisfação, uma vez que diminuiu a incerteza da venda e aumentou a expectativa de lucro.

Quando perguntados sobre o rendimento mensal obtido com a atividade pesqueira, os entrevistados não sabiam quantificar um valor exato, pois segundo eles, a renda para quem vive da pesca varia conforme a "sorte" na maré. Por isso, as autoras optaram por delimitar as respostas para uma margem maior ou menor do que de um salário base, conforme resultados na Figura 3.

Figura 3 - Distribuição segundo frequência do rendimento mensal de pescadores e marisqueiras das comunidades de Patané e Camocim, Arez/RN

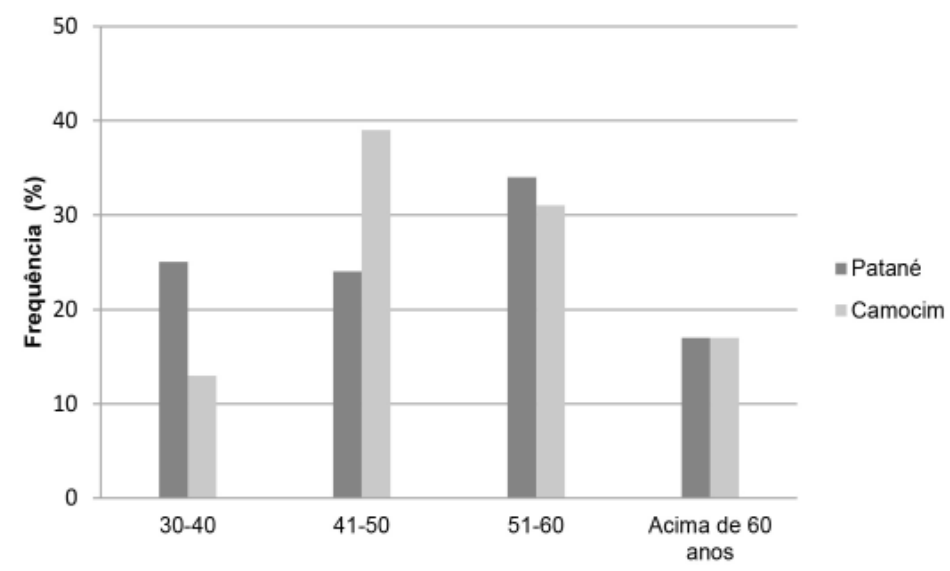

Fonte: Resultados da pesquisa de campo, 2014.

As informações obtidas demonstraram que os interlocutores, atualmente, possuem uma renda relativamente baixa; nos estudos realizados por Vasconcelos et al. (2003), Dias et al. (2007), Pedrosa (2007), Santos; Almeida- 
-Funo; Piga; França; Torres \& Melo (2011), Freitas; Pamplin; Legat; Fogaça \& Barros (2012) e Oliveira (2012) também foram encontradas o baixo rendimento com a pesca artesanal na Região Nordeste do Brasil. Assegura-se com isso a perspectiva de Woortmann (1991) de que a remuneração do trabalho oferecida por esse mercado é, contudo, insuficiente para repor, pela via mercantil, a fartura antes assegurada pela via do autoconsumo, especialmente a mulher que continuou coletando, mas o sentido dessa atividade se transformou.

Nas comunidades de Patané e Camocim, não é comum a complementação de renda com outras atividades extrativistas relacionadas à pesca. Durante a pesquisa de campo, apenas cinco pescadores relataram trabalhar esporadicamente como serventes ou pedreiros, mas isso ocorre apenas quando a safra de peixes está muito fraca na maré, ou seja, quando não se consegue capturar quantidades que sejam suficientes para a venda e para o alimento familiar.

A diferença entre os períodos de safra e entressafra pode influenciar no lucro dos pescadores, demonstrando variações na renda obtida (LIMA; DORIA \& FREITAS, 2012). Contudo, como nas duas comunidades a maioria dos pescadores não exerce outras atividades nos períodos de entressafra, o recebimento do seguro desemprego se torna de extrema importância, já que a captura de algumas espécies fica proibida no seu período de reprodução ou defeso biológico.

De acordo com os dados obtidos nas entrevistas, o seguro desemprego não é repassado para os associados da Colônia (Z-29) há quase oito anos. Segundo os interlocutores, o motivo para esse entrave burocrático foi uma denúncia anônima, feita junto à Secretaria de Estado da Agricultura, da Pecuária e da Pesca (SAPE/RN), devido a alguns associados não estarem exercendo realmente a pesca de forma profissional e como meio de sobrevivência. No entanto, os responsáveis pela Colônia (Z-29), afirmaram que de acordo com as autoridades, a não captura das espécies não está sendo contempladas pelo defeso biológico, implicando no não recebimento do seguro desemprego.

Na percepção de Marinho (2009), o seguro desemprego é concedido apenas para os pescadores de determinadas espécies, mas de uma forma geral, todos os pescadores interessados passam a ratificar que pescam a espécie na época do defeso apenas com o intuito de receber o benefício. Diante dessa circunstância, o maior problema encontrado na concessão do seguro desemprego não é a própria concessão, mas a emissão da Carteira Profissional de Pescador para aqueles que não comprovam o exercício da atividade e, por isso, as acusações de fraudes em todo o Brasil são tão comuns (MAIA; PEREIRA, 2010).

No que concerne à Colônia de Pesca (Z-29), esta é a única existente no município de Arez e, segundo levantamento do ano 2013, a instituição possui aproximadamente 200 associados, dos quais $64 \%$ residem nas comunidades de Patané e Camocim. A Colônia foi fundada em 1991 pelo seu atual presidente, mas até o momento não possui sede própria. $\mathrm{O}$ valor da contribuição mensal é $\mathrm{R} \$ 13,00$ reais, mesmo assim, a maioria dos associados está inadimplente com o pagamento da mensalidade e, de acordo com informações da administração da Colônia, apenas os associados do Distrito de Arez, que representam um menor número de cadastrados, efetuam o pagamento regularmente.

As Colônias de Pesca são organizações sociais que representam a classe trabalhista dos pescadores e que tem o papel de intervir a favor da atividade pesqueira, perante o governo brasileiro, desde 1846 (BEGOSSI, 2002). Após análise das interlocuções, verificou-se que um dos principais motivos para os associados de Patané e Camocim não efetuarem o pagamento da mensalidade está justamente atrelado ao não recebimento do seguro desemprego no período 
de defeso biológico. Além do que, alguns associados questionam a atuação política da Colônia (Z-29) em favor dos direitos trabalhistas dos pescadores e marisqueiras das comunidades.

O entrave burocrático para receber o seguro desemprego tem gerado outro problema para a Colônia (Z-29), pois cerca de oito associados de Patané e três de Camocim pediram transferência para a Colônia de Tibau do Sul (Z-12). Quando perguntados sobre qual o motivo da mudança, todos responderam que assim procederam a fim de receber o seguro desemprego regularmente, porquanto, na opinião deles, o valor recebido é uma ajuda de custo para quem vive apenas da pesca no período de defeso. Como observam Capelesso e Cazella (2011), o seguro desemprego auxilia no financiamento de armadilhas e canoas, e até mesmo na reforma das residências e melhorias na qualidade de vida.

Em meio às dificuldades financeiras, os interlocutores ainda acreditam que o estuário da Lagoa de Guaraíra é um presente de Deus e que ela é a "mãe da pobreza". Na opinião de Miller (2012) os pescadores e as marisqueiras de Patané e Camocim acreditam que tanto os peixes quanto os lilius são uma dádiva, e que por isso são inesgotáveis, pois o que é de origem divina o homem não acaba.

A religiosidade é uma tradição histórica do município de Arez, principalmente no segmento católico. No intuito de confirmar essa filiação religiosa entre os interlocutores, constataram-se através das entrevistas que em Patané, $71 \%$ dos entrevistados são católicos e em Camocim, $65 \%$. Apesar de o catolicismo ser forte em Arez, o carisma dessa religião vinha perdendo seguidores para outras doutrinas. Porém, segundo relatos, com a mudança do padre responsável em 2013, nativo e mais carismático, as pessoas estão voltando a frequentar a missa e a participar dos festejos cristãos, que são culturalmente importantes para os moradores da comunidade.

De acordo com Souto (2004), a forte religiosidade nas comunidades pesqueiras, a estreita dependência que tem do manguezal, aliada à falta de alternativas econômicas, produzem uma situação propícia ao estabelecimento da manutenção da fé como sinônimo de continuidade na oferta dos recursos naturais. Como enfatiza Silva (2011), a natureza não é uma realidade em si, mas uma realidade criada e transformada, assim, a Lagoa de Guaraíra se transforma e assume, perante a crença dos pescadores e marisqueiras, uma postura divina e, a partir disso, denota-se a importância da religiosidade para as comunidades estudadas.

Partindo para a observância de estratégias adaptativas na exploração do ambiente lagunar, Miller (2012) aponta que essas comunidades se organizam de acordo com a abundância ou escassez dos recursos disponíveis diante das necessidades socioeconômicas. Com o intuito de verificar a percepção dos pescadores e marisqueiras em relação aos recursos disponíveis no estuário da Lagoa de Guaraíra, foi perguntado se na opinião deles a pesca tinha aumentado ou diminuído nos últimos anos.

Logo, os resultados apontaram que em Patané, $51 \%$ dos interlocutores acham que a pesca aumentou e $49 \%$ acham que diminuiu; já em Camocim, $57 \%$ acham que a pesca diminuiu e $43 \%$ que aumentou. Contudo, segundo os discursos, compreende-se que houve um aumento do número de pescadores e o declínio dos recursos pesqueiros, conforme ilustram os relatos:

"Como aumentou os pescadores, o peixe diminuiu, hoje é difícil você pegar grandes quantidades." (Entrevistado n 4 - Pescador há 62 anos)

"Hoje tem muito pescador para pouco peixe." (Entrevistado $n^{\circ} 8$ - Pescador há 32 anos) 
"Hoje tá mais fácil ser pescador, mas também tá mais difícil pegar peixe.” (Entrevistada no 11 - Pescadora e Marisqueira há 40 anos)

Apesar de as áreas de pesca e mariscagem estarem inseridas na APA Bonfim-Guaraíra, os interlocutores relatam que desde 1999, quando a área de proteção foi implantada, não houve investimento em melhorias para uma gestão compartilhada por parte do órgão ambiental responsável e nem pela Prefeitura Municipal, a fim de evitar a degradação ambiental no estuário.

Os principais problemas relacionados com a APA Bonfim-Guaraíra declarados pelos entrevistados (Tabela 1), em relação aos últimos 15 anos, foram: desmatamento; proibição de acesso às áreas de pesca; construção dos viveiros de camarão; contaminação da Lagoa de Guaraíra pelos efluentes provenientes da carcinicultura e da usina de cana-de-açúcar; pesca predatória dos mariscos pelos pernambucanos e o aumento dos passeios turísticos de barco em Tibau do Sul/RN.

Tabela 1 - Problemas ambientais relacionados à APA Bonfim-Guaraíra declarados pelos pescadores e marisqueiras das comunidades de Patané e Camocim, Arez/RN

\begin{tabular}{|c|c|c|c|}
\hline Comunidades & Problema & Causa & Consequência \\
\hline \multirow{5}{*}{$\begin{array}{c}\text { Patané e } \\
\text { Camocim }\end{array}$} & $\begin{array}{l}\text { Desmata- } \\
\text { mento }\end{array}$ & $\begin{array}{l}\text { Construção } \\
\text { dos Viveiros } \\
\text { de Camarão }\end{array}$ & $\begin{array}{l}\text { Degradação Ambiental } \\
\text { do manguezal (APP) } \\
\text { e comprometimento } \\
\text { das espécies de peixes, } \\
\text { moluscos e crustáceos. }\end{array}$ \\
\hline & $\begin{array}{c}\text { Proibição } \\
\text { do acesso às } \\
\text { áreas de Pesca }\end{array}$ & $\begin{array}{l}\text { Proprietários } \\
\text { dos viveiros } \\
\text { de camarão }\end{array}$ & $\begin{array}{l}\text { Dificuldade para os pescado- } \\
\text { res se deslocarem ao ancora- } \\
\text { douro de suas embarcações, } \\
\text { visto que passam por dentro } \\
\text { das fazendas de camarão. }\end{array}$ \\
\hline & $\begin{array}{l}\text { Poluição dos } \\
\text { corpos hídri- } \\
\text { cos (Lagoa } \\
\text { de Guaraíra e } \\
\text { rios afluentes } \\
\text { Jacu e } \\
\text { Baldum) }\end{array}$ & $\begin{array}{l}\text { Lançamento } \\
\text { de agrotóxicos } \\
\text { e vinhoto } \\
\text { (usina de } \\
\text { cana-de- } \\
\text {-açúcar) e do } \\
\text { metabissulfito } \\
\text { de sódio (car- } \\
\text { cinicultura) }\end{array}$ & $\begin{array}{l}\text { Comprometimento da } \\
\text { sobrevivência da biota } \\
\text { aquática, como peixes, } \\
\text { moluscos e crustáceos. }\end{array}$ \\
\hline & $\begin{array}{l}\text { Extração } \\
\text { predatória } \\
\text { dos mariscos } \\
\text { (lilius) }\end{array}$ & $\begin{array}{l}\text { Técnica } \\
\text { proveniente de } \\
\text { atravessadores } \\
\text { pernam- } \\
\text { bucanos }\end{array}$ & $\begin{array}{l}\text { Comprometimento da } \\
\text { reprodução e sobrevivência } \\
\text { da espécie de molusco } \\
\text { Anomalocardia brasiliana. }\end{array}$ \\
\hline & $\begin{array}{l}\text { Conflitos } \\
\text { entre pescado- } \\
\text { res e empresas } \\
\text { de passeios } \\
\text { turísticos }\end{array}$ & $\begin{array}{l}\text { Turismo na } \\
\text { Lagoa de } \\
\text { Guaraíra } \\
\text { desenvolvido } \\
\text { pelo municí- } \\
\text { pio de Tibau } \\
\text { do Sul/RN }\end{array}$ & $\begin{array}{l}\text { Riscos de acidentes, dani- } \\
\text { ficação das redes de pesca, } \\
\text { além do barulho dos motores } \\
\text { afugentarem os cardumes. }\end{array}$ \\
\hline
\end{tabular}

Cabe salientar que os impactos da carcinicultura foram mais intensos entre os anos 2000 a 2007, uma vez que no ano de 2008 foi realizada uma operação de fiscalização e autuação dos proprietários dos viveiros de camarão construídos na APA Bonfim-Guaraíra, devido ao fato de que muitos dos empreendimentos estavam inseridos em Área de Preservação Permanente (APP) e, 
portanto, tinham sido construídos e operavam sem licença ambiental ou ainda com a licença vencida. Esses empreendimentos foram desativados e/ou notificados para que fossem recuperadas as áreas inseridas em APP.

Segundo relatos dos interlocutores, com a desativação dos viveiros, os conflitos locais diminuíram assim como o acesso à área de pesca melhorou. Após seis anos em recuperação, a vegetação do mangue está crescendo e a fauna aos poucos volta a se reproduzir como antes. Porém, ainda persistem consequências, principalmente para as espécies de moluscos, que no entendimento das marisqueiras são mais frágeis as mudanças no estuário o que implica na sua escassez.

A espécie de moluscos mais afetada pela atividade da carcinicultura foi a ostra (Crassostrea rhizophora) já que atualmente é difícil encontrá-la no mangue, porquanto com o desmatamento para a construção dos viveiros esses moluscos não sobreviveram. Segundo relatos, as ostras se desenvolvem nas raízes do mangue, onde se alimentam do lodo e, enquanto comem, vão filtrando e purificando a água, portanto, sem vegetação de mangue, morrem devido à falta de alimento e à forte incidência do sol.

Durante a pesquisa de Miller (2012), constatou-se que havia famílias especializadas apenas na extração de ostras, por ser um molusco de difícil coleta, que possui um valor agregado de mercado considerável e que eram muito solicitadas pelos restaurantes da região. Porém, com a interferência na reprodução das ostras, as famílias passaram a coletar apenas os lilius, pois estes não sofreram decaimento na reprodução e, além disso, são uma espécie mais fácil de coletar em grandes quantidades.

Nos últimos anos, todo o molusco extraído para a venda nas comunidades são os lilius, que até o momento não faltam na maré, porém vêm sofrendo forte pressão antrópica, devido à extração predatória para venda no mercado de Pernambuco. Essa nova realidade é percebida no discurso da marisqueira quando fala da coleta e venda dos lilius, em substituição às ostras:

\footnotetext{
"Os viveiros sempre botavam aqueles produtos que matam os bichos da maré... as ostras... hoje em dia o povo procura muito, mas não tem mais... hoje o que tem mais mesmo é o marisco (liliu). Antes, quando não tinha muito viveiro a gente tirava ostra, mas com o tempo foi acabando... por isso mudei... hoje só tiro o liliu mesmo. A ostra dava mais dinheiro, naquele tempo a ostra era 15 reais $(1 \mathrm{Kg})$, hoje custa 17 reais (1 Kg), o povo ainda procura... mas é muito difícil encontrar... não tem mais" (entrevistada $\mathrm{n}^{\circ} 3$ - Marisqueira há 33 anos).
}

Com base no diálogo das entrevistas semiestruturadas e observações dos interlocutores, foram identificadas e desenvolvidas categorias de dificuldades e perspectivas para quem vive da pesca nas comunidades de Patané e Camocim, conforme apresentadas na Tabela 2: 


\begin{tabular}{c|c}
\hline Dificuldades & Perspectivas \\
\hline $\begin{array}{c}\text { Colônia (Z-29) não pos- } \\
\text { suir sede própria }\end{array}$ & Construção de uma sede própria \\
\hline $\begin{array}{c}\text { Não recebimento do } \\
\text { seguro desemprego }\end{array}$ & Regularização do seguro desemprego \\
\hline $\begin{array}{c}\text { Falta de interesse da presi- } \\
\text { dência da Colônia (Z-29) }\end{array}$ & $\begin{array}{c}\text { Implantação de uma fábrica de bene- } \\
\text { ficiamento do pescado/marisco }\end{array}$ \\
\hline $\begin{array}{c}\text { Falta de interesse dos pes- } \\
\text { cadores e marisqueiras }\end{array}$ & $\begin{array}{c}\text { Comercialização dos lilius aos } \\
\text { atravessadores pernambucanos }\end{array}$ \\
\hline Falta de investimento da Prefeitura & Construção/reforma de residências \\
\hline \multicolumn{2}{c}{ Fonte: As autoras, 2014 }
\end{tabular}

Quando questionados sobre as principais dificuldades ou problemas cotidianos enfrentados por quem depende exclusivamente da pesca para sobreviver e manter a família, o não recebimento do seguro desemprego foi apontado como principal dificuldade atual. Esse acréscimo na renda desses trabalhadores é propiciado pela política pública (Lei $\mathrm{n}^{\circ} 10.779 / 2003$ ), a qual dispõe sobre concessão do benefício de seguro desemprego, durante o período de defeso, ao pescador profissional que exerce a atividade pesqueira de forma artesanal.

Como enfatiza Capelleso e Cazella (2011), o ganho desse direito é de grande relevância, principalmente para as famílias que não possuem renda extra ou benefícios previdenciários, como cerca de $60 \%$ do total de entrevistados das comunidades de Patané e Camocim. Além do que, segundo Lima; Doria $\&$ Freitas. (2012), o pagamento do seguro desemprego é um dos principais benefícios que os pescadores buscam ao se filiarem às organizações de pesca.

A regularização do seguro desemprego é um anseio dos pescadores e marisqueiras, pois devido ao enfraquecimento da pesca (falta peixe para comercialização), a maior parte da renda obtida vem da venda dos lilius aos atravessadores pernambucanos, momento relatado, principalmente pelas marisqueiras, como uma "bênção" para quem coleta moluscos. Segundo Capelleso e Cazella (2011), o dinheiro do seguro desemprego contribui como uma renda extra, inclusive para a utilização em melhoria das armadilhas, canoas e reforma de casas.

A falta de uma sede própria da Colônia (Z-29) também foi apontada como um problema, pois dificulta realizar encontros regulares com os associados, e nas poucas reuniões, quando tem, é preciso reservar uma sala de aula numa escola próxima ou utilizar a própria residência do presidente da Colônia.

Logo, a construção de uma sede para a Colônia (Z-29) seria uma melhoria, já que facilitaria o controle de pagamento da mensalidade de $\mathrm{R} \$ 13,00$ reais, além dos pedidos e emissão de carteiras profissionais. Com a estrutura da sede, também seria possível retomar o controle do pescado capturado ao mês, prática que segundo o tesoureiro da Colônia, fica difícil sem ter um lugar fixo como ponto de apoio aos pescadores.

Além disso, a Prefeitura de Arez não investe na principal atividade econômica do município. Segundo os interlocutores, eles nunca receberam nenhum tipo de ajuda para comprar/consertar uma armadilha ou canoa. Alguns dos entrevistados ainda anseiam por uma casa própria, mas relatam que a Prefeitura dificulta a venda de terrenos, por isso, muitas vezes, se tem de comprar o terreno de terceiros para construir as residências.

A implantação de uma fábrica de beneficiamento de pescado/marisco também foi relatada como uma alternativa para a pesca local e, como muitos 
pescadores não possuem condições de comprar um congelador (freezer), dificulta a conservação do peixe em grandes quantidades para posterior venda. Isso é reflexo da baixa renda de quase $50 \%$ dos entrevistados das duas comunidades, os quais afirmaram sobreviver com menos de um salário mínimo ao mês, não tendo, portanto, condições de investir em melhorias de trabalho.

Na opinião dos interlocutores, esses problemas ocorrem devido tanto à falta de interesse dos próprios associados, que não reivindicam seus direitos junto à Capitania dos Portos, quanto à falta de proatividade dos responsáveis pela Colônia (Z-29).

\section{CONCLUSÃO}

Os pescadores e marisqueiras das duas comunidades pesquisadas são homens e mulheres que se encontram na faixa etária entre 40 a 60 anos, possuem apenas o nível de ensino fundamental incompleto, são casados e têm filhos, residem em casa própria e sobrevivem com um rendimento mensal menor do que um salário mínimo.

Apesar de os interlocutores terem cadastro ativo na Colônia de Pesca (Z-29), eles enfrentam a dificuldade de não receber o seguro desemprego. Embora, segundo a legislação brasileira, o benefício se estenda a todos os pescadores artesanais registrados como profissionais da pesca, essa política estatal ainda não reverteu a essas comunidades como um mecanismo permanente que auxilie os pescadores e as marisqueiras no exercício de sua profissão.

Os pescadores são proprietários de armadilhas (redes e tarrafas) e das pequenas embarcações (canoas). As principais dificuldades encontradas na execução de suas atividades é a falta de uma sede própria para a Colônia (Z-29) e de uma fábrica de beneficiamento para o peixe/marisco. O desenvolvimento de ações de beneficiamento e conservação de pescado agregaria valor ao produto e consequentemente aumentaria o lucro com a venda desses recursos.

Os resultados apresentados permitem concluir que para as duas comunidades estudadas e instaladas às margens da Lagoa de Guaraíra, o pescado e, principalmente, os moluscos (lilius), são os principais recursos explorados para a alimentação e comercialização.

As comunidades de pesca são tradicionalmente consideradas de pequena escala, devido ao seu sistema de produção e venda serem direcionadas apenas à sobrevivência. No entanto, nos últimos anos, a organização e a divisão social do trabalho têm sofrido modificações que denotam a influência de um sistema de produção e venda direcionado ao mercado externo, mais precisamente, ao mercado pernambucano, em se tratando da exploração predatória dos lilius.

Desta forma, a atividade pesqueira segue enfrentando entraves técni$\cos$, burocráticos e financeiros, em que a necessidade cotidiana de homens e mulheres é o fator determinante na disposição de continuar exercendo a pesca ou mariscagem no estuário da Lagoa de Guaraíra.

\section{AGRADECIMENTOS}

As autoras agradecem aos pescadores e marisqueiras de Patané e Camocim e aos demais interlocutores locais que forneceram as informações e apoiaram o desenvolvimento desta pesquisa. Também agradecemos à Uni- 
versidade Federal do Rio Grande do Norte (UFRN), em especial ao Programa de Pós-Graduação em Desenvolvimento e Meio Ambiente (PRODEMA) e à Coordenação de Aperfeiçoamento de Pessoal de Nível Superior (CAPES) pela concessão da bolsa de estudo.

\section{NOTAS}

${ }^{1}$ Nome popular local dado aos moluscos (mariscos) da espécie Anomalocardia Brasiliana.

\section{REFERÊNCIAS}

ALENCAR, C. A. G. de; MAIA, L. P. Perfil Socioeconômico dos Pescadores Brasileiros. Arq. Ciên. Mar, 44(3): 12 - 19. Fortaleza, 2011.

ANGROSINO, M. Etnografia e observação participante. Porto Alegre: Artmed, 2009.

BEAUD, S; WEBER, F. Guia para a pesquisa de campo: produzir e analisar dados etnográficos. Tradução de Sérgio Joaquim de Almeida. Revisão de tradução de Henrique Caetano Nardi. Petropólis, RJ: Vozes, 2007.

BEGOSSI, A. Latin América Fisheries: Local organization and management. Tunisia: Latin América Fisheries, ISEE, 6-9, 2002.

BRASIL. Lei $n^{\circ} 10.779$, de 25 de Novembro de 2003. Dispõe sobre a concessão do benefício de seguro desemprego, durante o período de defeso, ao pescador profissional que exerce a atividade pesqueira de forma artesanal. Brasília: DOU de 26/11/2003.

CAPELLESSO, A. J; CAZELLA, A. A. Pesca Artesanal entre crise econômica e problemas socioambientais: estudo de caso nos municípios de Garopaba e Imbituba (SC). Ambiente \& Sociedade. v. XIV, n. 2, jul/dez. 2011.

CHIZZOTTI, A. Pesquisas em ciências humanas e sociais. 11. ed. São Paulo: Cortez, 2010.

CORREA, S. M. B. B. Probabilidade e estatística. 2. ed. Belo Horizonte: PUC Minas Virtual, 2003.

CRESWELL, J. W. Projeto de Pesquisa: métodos qualitativo, quantitativo e misto. Tradução Magda Lopes. Consultoria, supervisão e revisão técnica desta edição Dirceu da Silva. 3. ed. Porto Alegre: Artmed, 2010.

DIAS, T. L. P.; ROSA, R. S.; DAMASCENO, L. C. P. Aspectos socioeconômicos, percepção ambiental e perspectivas das mulheres marisqueiras da Reserva de Desenvolvimento Sustentável Ponta do Tubarão (Rio Grande do Norte, Brasil). Gaia Scientia, 1(1): 25-35, 2007.

DIEGUES, A. C. A pesca construindo sociedades: leituras em antropologia marítima e pesqueira. São Paulo: NUPAUB, 2004.

FOOD AND AGRICULTURE ORGANIZATION OF THE UNITED NATIONS (FAO). FAO statistical year book 2012: world food and agriculture. Roma: 2012. Disponível em: http://www.fao.org/docrep/015/i2490e/i2490e00.htm. Acesso em: ago. 2013.

FLICK, U. Introdução à pesquisa qualitativa. 3. ed. Porto Alegre: Artmed, 2009.

FREITAS, S. T; PAMPLIN, P. A. .Z; LEGAT, J; FOGAÇA, F. H. S; BARROS, R. F. M. Conhecimento Tradicional das Marisqueiras de Barra Grande, Área de Proteção Ambiental do Delta do Rio Parnaíba, Piauí, Brasil. Ambiente \& Sociedade. São Paulo v. XV, 2, 91-112, mai/ago, 2012. 
HARAYASHIKI, C. A. Y; FURLAN, F. M; VIEIRA, J. P. Perfil Socioeconômico dos Pescadores da Ponte dos Franceses, Rio Grande, RS, Brasil. Bol. Inst. Pesca, São Paulo, 37(1): 93 - 101. 2011.

INSTITUTO BRASILEIRO DO MEIO AMBIENTE E DOS RECURSOS NATURAIS RENOVÁVEIS (IBAMA). Boletim estatístico da pesca marítima e estuarina do estado do Rio Grande do Norte - 2008. Tamandaré: CEPENE, 2009-2010.

INSTITUTO DE DESENVOLVIMENTO SUSTENTÁVEL E DO MEIO AMBIENTE DO RIO GRANDE DO NORTE (IDEMA). Caracterização da Pesca Artesanal do Estado do Rio Grande do Norte. Natal, RN. 2004.

. Perfil do seu município - Arez. Natal, RN. 2008.

LIMA, M. A. L; DORIA, C. R. C; FREITAS, C. E. C. Pescarias Artesanais em Comunidades Ribeirinhas na Amazônia Brasileira: Perfil Socioeconômico, Conflitos e Cenário da Atividade. Ambiente \& Sociedade. São Paulo v. XV n. 2. 73-90, mai/ago, 2012.

MAIA, M. B; PEREIRA, H. S. A inclusão do pescador nas políticas públicas de seguridade social do trabalhador rural. Anais [...] do $2^{\circ}$ Encontro da Sociedade Brasileira de Sociologia, UFPA, Belém (PA), 13 a 15 de setembro de 2010.

MARINHO, M. S. Pesca artesanal, defesos de pesca e unidades de conservação. Anais [...] do I Encontro Nacional de Antropologia do Direito (ANADIR). USP, 20 a 21 de agosto de 2009.

MATOS, C. L. G. de. A abordagem etnográfica na investigação científica. UERJ, 2001. Disponível em: http://www.ines.org.br Acesso em: set. 2013.

MILLER, F. S. Barra de Tabatinga: terra do povo, mar de todos: a organização social de uma comunidade de pescadores do litoral do Rio Grande do Norte. Natal: EDUFRN, 2002.

. Pescadores e Coletoras de Patané/Camocim: aspectos da adaptação humana aos manguezais do Rio Grande do Norte. Natal: EDUFRN, 2012.

MINISTÉRIO DA PESCA E AQÜICULTURA (MPA). Registro Geral dos Pescadores - RGP. Brasília/DF: MPA, 2010. 2012.

. Boletim estatístico da pesca e aqüicultura. Brasil 2010. Brasília: MPA,

. Pesca Artesanal. Brasília: MPA, 2013. Disponível em: http://www. mpa.gov.br/pescampa/artesanal. Acesso em: 15 set. 2013.

OLIVEIRA, B. M. C. de. Percepção Ambiental dos Pescadores de Marisco do Litoral Norte de Pernambuco. Anais [...] do III Congresso Brasileiro de Gestão Ambiental. Goiânia/GO, 19 a 22 de novembro de 2012.

OLIVEIRA, O. M. B. A. de; SILVA, V. L, da. O Processo da Industrialização do Setor Pesqueiro e a Desestruturação da Pesca Artesanal no Brasil a partir do Código de Pesca de 1967. Sequência, 65, 329-357, 2012.

PEDROSA, R. A. Pesca, perfil socioeconômico e percepção ecológica dos pescadores artesanais de Porto de Galinhas (PE). Recife. Dissertação (Mestrado em Oceanografia) - UFPE, 2007.

PEREIRA, L. C. C; FILHO, P. W. M. S; RIBEIRO, M. J. S; PINHEIRO, S. C. C; NUNES, Z. M. P; COSTA, R. M. Dinâmica socioambiental na Vila dos Pescadores (Amazônia Oriental, Pará, Brasil). Desenvolvimento e Meio Ambiente, 13, 125-136, jan/jun. 2006.

PEREIRA, L. C. C; SILVA, I. R. S; COSTA, R. M. Uso e ocupação em uma comunidade pesqueira na margem do estuário do Rio Caeté (PA, Brasil). Desenvolvimento e Meio Ambiente, 13, 11-18, jan/jun. 2006

SALES, T. E. A. de. Localização das comunidades de Patané e Camocim. Arez/ RN, 2014. 1 Figura. 
SANTOS, P. V. C. J; ALMEIDA-FUNO, I. C. S; PIGA, F. G; FRANÇA, V. L; TORRES, S. A; MELO, C. D. P. Perfil Socioeconômico de Pescadores do Município da Raposa, Estado do Maranhão. Rev. Bras. Eng. Pesca 6(1): I-XIV, 2011.

SILVA, E. F. da. Influência do Turismo sobre a atividade pesqueira do municipio de Tibau do Sul - RN. Natal. Dissertação (Mestrado em Desenvolvimento e Meio Ambiente) - UFRN, 2011.

SILVA, R. E. da. Sob o olhar do mangue: ensaio sociológico sobre a relação homem-natureza mediada por uma narrativa mítica. João Pessoa: Ideia, 2011.

. Guiados por mares e peixes: memória social, inovação tecnológica, e o processo de fragmentação na pequena pesca comercial simples em duas comunidades costeiras do Rio Grande do Norte. João Pessoa. Tese (Doutorado em Sociologia) - UFPB, 2012.

SOUTO, F. J. B. A ciência que veio da lama: uma abordagem etnoecológica abrangente das relações ser humano/manguezal na comunidade pesqueira de Acupe, Santo Amaro - BA. São Carlos. Tese (Doutorado em Ecologia e Recursos Naturais) - UFSCar, 2004.

SOUZA, K. M ; ARFELLI, C. A; GRAÇA LOPES, R. Perfil Socioeconômico dos Pescadores de Camarão-Sete-Barbas (Xiphopenaeus Kroyeri) da Praia do Perequê, Guarujá (SP). B. Inst. Pesca, São Paulo, 35(4): 647 - 655, 2009.

WOORTMANN, L.F. Da Complementariedade a Dependência: a mulher e o ambiente em comunidades "pesqueiras" do Nordeste. Série Antropologia. Brasília, 1991.

. O ambiente e a mulher: O caso do Litoral Norte do Rio Grande do Norte, Brasil. Latin America Studies, 12, 1992. The Association for America Studies. Tokyo. Japan. 1992. 